\title{
Editorial
}

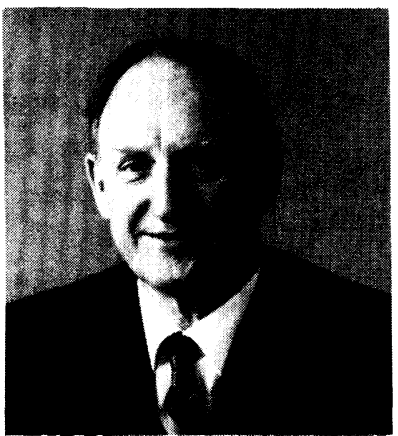

\section{Kingslake Medal and Prize}

This is the time of year that I have the opportunity in my editorial to congratulate the winner of the Rudolph Kingslake Medal and Prize for the best paper published in Optical Engineering during 1991. The winner was Brian E. Newnam for his paper "Extreme ultraviolet free-electron laser-based projection lithography systems." Our sincere congratulations to Dr. Newnam on this major award. Brian Newnam is a member of SPIE and works at the Chemical and Laser Science Division of the Los Alamos National Laboratory.

The selection committee, who had the difficult task of choosing one winning paper, consisted of Malgorzata Kujawińska, Jean Bulabois, Freeman Hall, Satoshi Ishihara, and Bruce Steiner, who acted as chair. Richard Hoover's schedule prevented his taking part in the deliberations. This was just as well, perhaps, since the winning paper was part of the August 1991 special section devoted to X-Ray/EUV Optics, of which Richard Hoover was the guest editor.

As readers of this editorial may know, I have a special feeling for the Kingslake award. I helped to get this award started, and it is named for a very special colleague of mine in Rochester for whom I have enormous respect. I had the great honor of receiving the award myself with David B. Kay in 1977 and also the opportunity to serve on the selection committee in 1981.

Dr. Newnam's award-winning paper was not only part of a special section of our journal but also was, as the footnote to the paper states, "a revision of a paper presented at the SPIE conference on X-Ray/EUV Optics in Astronomy, Microscopy, Polarimetry, and Projection Lithography, July 1990, San Diego, California." This fact would count as one point in favor of our current policy regarding the publication of revised proceedings papers.

Let me close by once again congratulating Brian Newnam for his excellent prize-winning contribution to Optical Engineering. This paper is a symbol of the quality of our journal and is particularly special to me since it was published during my first year as editor.

Brian J. Thompson Editor

\section{Rudolf Kingslake Medal and Prize}

Past Recipients

1974 Irving R. Abel and B. R. Reynolds

1975 J. M. Burch and C. Forno

1976 Richard E. Swing

1977 David B. Kay and Brian J. Thompson

1978 Norman J. Brown

1979 J. R. Fienup

1980 G. Ferrano and G. Hausler

1981 Robert A. Sprague and William D. Turner

1982 David M. Pepper

1983 James R. Palmer
1984 Gene R. Gindi and Arthur F. Gmitro

1985 Armand R. Tanguay, Jr.

1986 Arthur D. Fisher, Lai-Chang Ling, John N. Lee, and Robert C. Fukuda

1987 Chris P. Kirk

1988 Ares J. Rosakis, Alan T. Zehnder, and Ramaratnam Narasimhan

1989 Pochi Yeh, Arthur Chiou, John Hong, Paul H. Beckwith, Tallis Chang, and Monte Khoshnevisan

1990 Paul R. Prucnal and Philippe A. Perrier 
September 1992

Wavelet Transform

Harold H. Szu

U.S. Navy

Naval Surface Warfare Center, Code R44

10901 New Hampshire Ave.

Silver Spring, MD 20903-5000

301/394-3097 • 301/394-3923 FAX

October 1992

Acousto-Optics

Ting-Chung Poon

Virginia Polytechnic Institute and

State University

Bradley Department of Electrical Engineering

Optical Image Processing Laboratory

Blacksburg, VA 24061

703/231-4876 • 703/231-3362 FAX

\section{November 1992}

Relay Mirror Experiment

Paul W. Kervin

Phillips Laboratory

535 Lipoa Parkway, Suite 200

Kihei, HI 96753

808/874-1542 • 808/874-1640 FAX

\section{December 1992}

Automatic Target Recognition

Firooz Sadjadi

Systems and Research Center

Honeywell Inc.

3660 Technology Drive

Minneapolis, MN 55418

$612 / 782-7543 \cdot 612 / 782-7438 \mathrm{FAX}$

January 1993

Optical Research in Asia

Chung J. Kuo

National Chung Cheng University

Department of Electrical Engineering

Chiayi, Taiwan 62107

886-5-272-0411, ext. 6210 • 886-5-272-0862 FAX

Toshimitsu Asakura

Hokkaido University

Research Institute of Applied Electricity

Sapporo, 060 Japan

81-11-716-2111 - 81-11-758-3173 FAX

Yong H. Lee

KAIST Department of Physics

Yusung-Ku, Taejon, Korea

82-42-829-2536 • 82-42-861-1458 FAX

Run W. Wang

Shanghai Institute of Optics and Fine Mechanics

P.O. Box 800-211

Shanghai, 201800 China
March 1993

Optical Fiber Reliability II

Hakan H. Yuce

Belloore

445 South Street

Morristown, NJ 07962

201/829-4945 - 201/267-9753 FAX

Charles R. Kurkjian

AT\&T Bell Laboratories

600 Mountain Avenue

Murray Hill, NJ 07960-1910

908/582-2378 - 908/582-2783 FAX

April 1993

Emerging Optoelectronic Technologies

Vijai K. Tripathi

Oregon State Univeristy

Dept. of Electrical and Computer Eng.

ECE Building 220

Corvallis, Oregon 97331-3211

503/737-3617 • 503/737-1300 FAX

Manuscripts due Sep. 1, 1992

May 1993

Phase Contrast Microscopy

Maksymilian Pluta

Institute of Applied Optics

ul. Kamionkowska 18

03-805 Warszawa, Poland

4822184405 or 4822184497

4822133265 FAX

Manuscripts due Oct. 1, 1992.

June 1993

From Numerical to Symbolic Image Processing: Systems \& Applications

G. Vernazza

Dipartimento di Ingegneria Biofisica ed Elettronica

Universita degli Studi di Genova

Via Opera Pia, 11a

16145 Genova Italy

+39 10353-2755 - +39 10 353-2777 FAX

Manuscripts due Oct. 15, 1992.

July 1993

Visual Communication and Image

Processing IV

Cheng-Tie Chen

Belloore

445 South St.

Morristown, NJ 07962

201/829-5151 • 201/829-5884 FAX

Hsueh-Ming Hang

Center for Telecommunication Research

National Chiao-Tung University

Hsinchu, Taiwan

$+886 / 35-712121 \times 3298 \bullet+886 / 35-723283$ FAX

Kou-Hu Tzou

COMSAT Labs.

22300 Comsat Drive

Clarksburg, MD 20871

301/428-4663 - 301/428-7747 FAX

Manuscripts due Dec. 1, 1992.

August 1993

Electro-Optical Flight Systems

Amar Choudry

Science and Technology Corporation

101 Research Drive

Hampton, VA 23666

804/865-1894

Manuscripts due Jan. 1, 1993.
September 1993

Optical Science and Engineering in Canada

C.P. Grover

National Research Council

Institute for National Measurement Standards

Ottawa, Canada K1A OR6

613/993-2098 • 613/952-1394 FAX

Manuscripts due Feb. 1, 1993.

October 1993

Microlithography

James R. Sheats

Hewlett-Packard Company

2500 Deer Creek Road

Palo Alto, CA 94304-1392

415/857-5987 • 415/857-6241 FAX

Manuscripts due March 1, 1993.

November 1993

Acquisition, Tracking, and Pointing

Mohammed A. Karim

University of Dayton

Center for Electro-Optics

300 College Park

Dayton, Ohio 45469-0227

513/229-2241 - 513/229-3433

Manuscripts due April 1, 1993.

December 1993

Magnetospheric Imagery and

Atmospheric Remote Sensing

Supriya Chakrabarti

University of California

Earth and Planetary Atmospheres Group

Space Sciences Lab

Berkeley, CA 94720

510/642-3524 • 510/643-7629 FAX

Manuscripts due May 1, 1993.

January 1994

Infrared Technology

Marija S. Scholl

Jet Propulsion Laboratory

California Institute of Technology

4800 Oak Grove Drive

Pasadena, CA 91009-8099

818/354-2313 • 818/393-6105 FAX

Manuscripts due June 1, 1993.

February 1994

Optical Interconnects and Packaging

Sing Lee

University of Califomia/San Diego

E\&CE Department

La Jolla, CA 92093-0407

619/534-2413 • 619/534-1225 FAX

Manuscripts due July 1, 1993.

March 1994

High Heat Flux Optical Engineering

Ali M. Khounsary

Argonne National Laboratory 2

Advanced Photon Source, APS 36

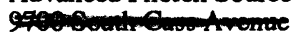

Argonne, II 60439 .

708/252-3384 - 708/252-3222 FAX

Manuscripts due Aug. 1, 1993. 


\title{
Optical Engineering in U.K. Industry
}

\author{
Lionel R. Baker \\ 21 Long Acre \\ Orpington, Kent \\ BR6 7RD, United Kingdom \\ Richard J. Parker \\ Rolls-Royce Applied Science Laboratory \\ P.O. Box 31 \\ Derby \\ DE2 8BJ, United Kingdom
}

More than four and a half years have passed since the first special issue on this subject graced these pages in January 1988. Now, as then, the editors have not attempted to provide a representative or comprehensive survey of the field, but have merely dipped into the rich fountain of activity and expertise in the United Kingdom. What is apparent from both this issue and its predecessor is the sheer diversity of the work: ranging from the latest in sensor technology to the fundamentals of lighting and from definition of new, basic standards to laser vibrometry.

The editors concentrated on papers either from the U.K. industry or from universities working on projects for industry. The reasoning behind this selection was to encourage papers from the usually more reserved industrial researchers, who do not seem to have the same propensity for publication as their academic counterparts.

The differences between this issue and the previous one are also worth noting. In 1988, only two of the papers featured fiber optic technology. In this issue, nearly half of the papers are concerned with applications of optical fibers. This shows the movement of fiber sensors during this period out of the laboratory and into the workplace. This change is also indicative of the confluence of fiber technology and other new, enabling technologies, such as the micromachining of silicon.

Other changes have also been apparent in the U.K. optical community. During this period, the U.K. Optical Engineering Advisory Panel was formed under the auspices of SPIE. This panel has organized, in conjunction with SIRA Ltd., many successful seminars that have sought to bring new developments in optical engineering to the attention of British industry.

Optical engineering still has some way to go in the United Kingdom before being fully recognized for the comprehensive discipline it has become. Several universities now have optoelectronic or optical engineering sections and departments. The research funding bodies, however, have not moved with the times, and would-be researchers in optical engineering must hunt for financial support among the subcommittees of more traditional disciplines, such as physics, electrical engineering, or mechanical engineering.

We hope that the reader will enjoy this selection of papers, and we thank the authors for their efforts. Several additional papers arrived too late for inclusion in this issue and may be published in subsequent issues of the journal. We also take this opportunity to thank the hard-working and unsung referees, without whose instructive and informed criticism the quality of work would not have been maintained.

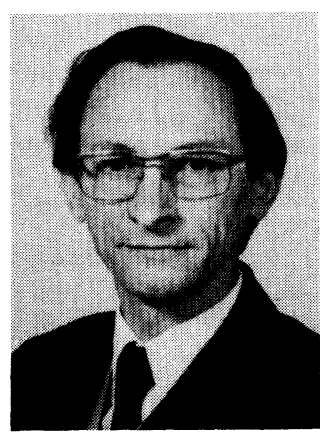

Lionel R. Baker graduated in physics from Imperial College, London, and joined Sira Ltd. in 1958. He was a founding member of the Sira Board of Directors and served from 1972 to 1991. He is named in 45 patent applications including a new method of dynamic stress measurement that resulted in two Queen's Awards for Technology and Exports. The author of 75 technical publications, he lectures regularly to international audiences on the industrial applications of optical technology and technology transfer. In addition to the development of instruments for measuring the optical transfer function, he has recently been responsible for producing a new standard for measuring surface damage. Dr. Baker is currently chairman of the British Standards Institution Committee CPM/17 "Fundamental Standards," convener of CEN.TC123/WG1 "Terminology and Test Methods for Lasers," and a member of ISO/TC172. Dr. Baker is a fellow of the Institute of Physics, SPIE, and OSA. He was executive editor of the Journal of Modern Optics for 17 years. He recently retired as technical director at Sira and now acts as an international consultant and visiting professor of Brunel University, London.

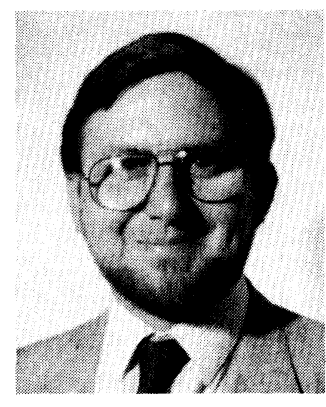

Richard J. Parker earned a BSc degree in physics from Imperial College, London, in 1975. From 1975 to 1978, he worked on an SERC-funded project to study thermoplastic materials for holography. The work was carried out at Imperial College and the National Physical Laboratory. He joined the Advanced Research Laboratory of Rolls-Royce plc., Derby, United Kingdom, in 1978 and in 1986 was appointed group leader of the Optical Sciences Group. The laboratory is now known as the Rolls-Royce Applied Science Laboratory. Parker is responsible for development of laser-based instrumentation. He has published over 20 papers on the subjects of holography and optical diagnostics for aeroengine research. In 1987 he won the International Gas Turbine Institute's JimKamman Awardand in 1991 the Royal Aeronautical Society's Ackroyd Stuart Award. His current research interests include holography, laser Doppler vibrometry, laser anemometry, particle image velocimetry, photomechanics, and nanotechnology. 